\title{
In vitro Detection of Antibacterial Activity of Glycyrrhizic Acid Nanoparticle against ESBL Producing Klebsiella pneumoniae strains
}

\author{
M. AbdEl-Mongy ${ }^{(1)}$, Amal S. Othman ${ }^{(2)}$ and Hamdy A. Elkhateeb ${ }^{(2) \#}$ \\ ${ }^{(1)}$ Microbial Biotechnology Department, Genetic Engineering and Biotechnology \\ Research Institute, University of Sadat City, Sadat City, Egypt; (2) Microbiology \\ Department, Faculty of Applied Medical Science, October $6^{\text {th }}$ University, Giza, Cairo, \\ Egypt.
}

\begin{abstract}
$\mathbf{E}$ XTENDED-spectrum $\beta$-lactamase (ESBL) producing Klebsiella pneumoniae strains can present resistance to many antibiotic groups due to resistant genes. This study conducted to detect and identify multi-drug resistant (MDR), ESBL producing $K$. pneumoniae strains from different clinical samples with detection and sequencing of both Temoneira (TEM) and sulfhydryl variable (SHV) genes and using Glycyrrhizic acid nanoparticle as an antimicrobial agent for ESBL producing $K$. pneumoniae strains. One hundred and fifty clinical specimens were processed. ESBL producing $K$. pneumoniae strains were detected by double disk synergy test. TEM and SHV genes responsible for MDR in K. pneumoniae were detected by polymerase chain reaction (PCR) and sequence alignment was done using DNA sequencing. The effect of different concentrations of Nano Glycyrrhizic acid was determined. K. pneumoniae was detected in $53.3 \%$ of the total collected samples $(80 / 150)$. Seventy one percent $(57 / 80)$ of them were found to be multi-drug resistant strains and 63\% (36/57) also found to contain the ESBL enzymes. Males were highly infected than females. TEM gene was detected in $52.8 \%$ of the ESBL isolates while SHV gene was detected in $72.2 \%$. Twenty Five percent of the ESBL producing K. pneumoniae was found to contain both TEM and SHV genes. Nucleic acid sequence alignment of both genes showed some mutations. Chloramphenicol was found to be the drug of choice to overcome ESBL producing K. pneumoniae with inhibition of $97.2 \%$. The antibacterial activity of Nano Glycyrrhizic acid revealed that $10 \mu \mathrm{g} / \mathrm{ml}$ was found to be the minimum bactericidal concentration (MBC) against ESBL producing $K$. pneumoniae isolates.
\end{abstract}

Keywords: Klebsiella pneumoniae, Glycyrrhizic acid, Multidrug-resistance.

\section{Introduction}

Klebsiella pneumoniae is considered as the main cause of nosocomial infections among Gramnegative bacteria, such as urinary tract, pneumonia, wound, septicemia and bloodstream infections (Arivett et al., 2015). It is very important to investigate the antimicrobial susceptibility pattern of Klebsiella in order to prevent the rapid spread of drug resistance (Namratha et al., 2015).

Extended-spectrum $\beta$-lactamases (ESBLs), multi-drug resistant $K$. pneumoniae contains virulence factors that cause treatment failure (Mustafa et al., 2017). ESBLs can hydrolyze $\beta$-lactam ring in $\beta$-lactam drugs by a nucleophilic attack (Papp-Wallace et al., 2011). The plasmids that encode the ESBL genes can also resist to
Aminoglycosides (Vuotto et al., 2014).

The antibiotic treatments against $K$. pneumoniae infections contain Aminoglycosides group such as Gentamycin, Quinolones group and $\beta$-lactams group such as Carbapenems and Cephalosporins (Qureshi, 2015). Some resistant K. pneumoniae strains can form biofilm that resist against $\beta$-lactams, Carbapenems, Trimethoprim/Sulfamethoxazole, Aminoglycosides and Fluoroquinolones (Kumar et al., 2011).

Nanoscale particles and molecules are a potential alternative for treatment of disease based on their structure and size, which differ from traditional small-molecule drugs (Wagner et al., 2006). Several pharmaceutical companies have obtained approval from the US Food and Drug

"Corresponding author email: hamdy.elkhateeb@yahoo.com

DOI: 10.21608/ejm.2018.5057.1072

(C)2018 National Information and Documentation Center (NIDOC) 
Administration (FDA) for the development of nanotechnology-based drugs. The global market for medical nanotechnology is expected to reach more than $\$ 3$ billion (Sahoo et al., 2008).

Glycyrrhizic acid (GA) is obtained from the roots of licorice plants (Glycyrrhiza glabra). It is a triterpene glycoside which presents active pharmacological and antimicrobial activity (Jianyuan et al., 2014). It was found that Glycyrrhetinic acid can be produced in the human body through metabolic processes. The pharmacological effect of GA is similar to Glycyrrhetinic acid (Yong, 2012). It was found that there are many useful secondary metabolites obtained such as alkaloids, saponins, and flavonoids due to the extraction of a Hydro-methanolic root (crude) from Glycyrrhiza glabra. All of these components are used as antibacterial and anti-oxidant ingredients (Sharma et al., 2013).

This study was aimed to detect and identify extended spectrum $\beta$-lactamase (ESBL) producing $K$. pneumoniae strains from two hospitals in Egypt. The study is concerned with the identification of specific genes in charge of resistance to a $\beta$-lactam antibiotic group and the detection of their sequences. In addition, the effects of some antibiotics from different groups were investigated to overcome ESBL producing $K$. pneumoniae, and also the effect of different concentrations of Glycyrrhizic acid nanoparticle for preventing and controlling ESBL producing $K$. pneumoniae strains.

\section{Materials and Methods}

\section{Clinical specimens}

One hundred and fifty different clinical specimens were included in this study (eight were from pus samples, thirty from blood samples, twenty from urine samples and ninety two from sputum samples). They were collected from different hospital departments; 120 samples from Intensive Care Unit, Coronary Care Unit, medical laboratory and Surgery department of ElSadr Hospital and 30 samples from the medical laboratory of National Cancer Institute in Egypt from April 2016 to January 2017. The required documents were submitted and approved according to the committee guidelines showed by Central Directorate of Research and Health Development in Egypt. All samples were processed by standard methods (Cheesbrough, 2000 and Baveja, 2012).
Ages of patients ranged from 20 to 60 years old. Both male and female patients were enrolled in this study to investigate the relationship between age, gender and prevalence of infection with $K$. pneumoniae.

\section{Microbiological analysis \\ Bacterial identification and confirmation by API 20 E test}

The samples were cultured on blood agar and MacConkey's agar media (Lab M, United Kingdom) and incubated at $37^{\circ} \mathrm{C}$ for $24 \mathrm{~h}$. All clinical isolates were examined morphologically for colony characteristics on agar media (Archana \& Harsh, 2011). K. pneumoniae were isolated and purified on MacConkey's agar media. Biochemical standard procedures were used (Cruickshank, 1980). API-20E (BioMerieux, USA) specific test was used to confirm the presence of $K$. pneumoniae.

\section{Antibiotic susceptibility test (disc diffusion)}

The isolated $K$. pneumoniae strains were tested against 19 different antibiotics (belonging to nine groups) for their susceptibility. The antibiotic groups include the Penicillins group (Ampicillin

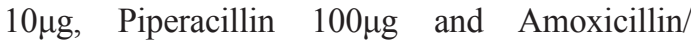
Clavulanic acid 20/10 $\mu$ g), Carbapenems

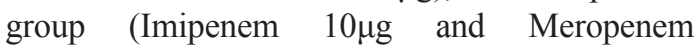
$10 \mu \mathrm{g}$ ), Monobactam group (Aztreonam $30 \mu \mathrm{g}$ ), Cephalosporins group (Cefaclor 30 $\mu \mathrm{g}$, Ceftazidime $30 \mu \mathrm{g}$, Cefotaxime $30 \mu \mathrm{g}$, Cefepime $30 \mu \mathrm{g}$, Ceftriaxone $30 \mu \mathrm{g}$ and Cefoperazone $75 \mu \mathrm{g}$ ), Quinolones group (Ciprofloxacin $5 \mu \mathrm{g}$

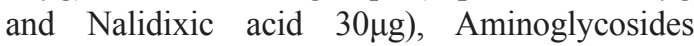

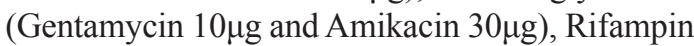

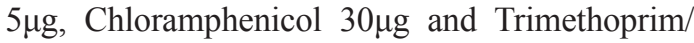
Sulphamathoxazole $1.25 / 23.7 \mu \mathrm{g}$ by Kirby- Bauer disc diffusion method on Mueller-Hinton agar medium (Oxoid, England) and interpreted using Clinical \& Laboratory Standards Institute (CLSI) Guidelines (Freeman et al., 2014).

Antibiotic discs were placed on MullerHinton agar plates inoculated with 0.5 McFarland inoculum performed from overnight cultured isolates. Plates were incubated at $37^{\circ} \mathrm{C}$ for $24 \mathrm{~h}$. Inhibition zone diameter was measured and compared to CLSI, 2014 criteria.

Detection of $K$. pneumoniae strains producing ESBL enzymes (ESBL screening)

The detection of ESBL producing $K$. pneumoniae strains was performed by using the Double Disk Synergy Test (DDST) as described 
by Jailer et al. (1988). Mueller Hinton agar plates were inoculated with a standardized inoculum of

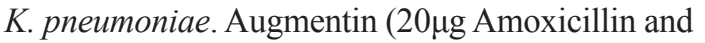
$10 \mu \mathrm{g}$ Clavulanic acid) disc was placed at the center of the inoculated plate. Three antibiotics from Cephalosporins $3^{\text {rd }}$ generation group (Cefotaxime $30 \mu \mathrm{g}$, Ceftriaxone $30 \mu \mathrm{g}$, Ceftazidime $30 \mu \mathrm{g})$ and one Monobactam (Aztreonam 30 $\mu$ g) discs were placed at $20 \mathrm{~mm}$ distance from Augmentin disc. Plates were incubated at $37^{\circ} \mathrm{C}$ for $24 \mathrm{~h}$. Positive results are indicated as an enhancing zone around the three combined antibiotics (Onur \& Durak, 2009).

\section{Genotypic characterization}

Preparation of genomic DNA and PCR procedures

Total bacterial DNA was extracted using the QIAamp DNAMini Kit(QIAGEN, USA). Template DNA of $K$. pneumoniae was prepared from freshly cultured isolates by culturing on $5 \mathrm{ml}$ brain heart broth medium at $37^{\circ} \mathrm{C}$ for $24 \mathrm{~h}$. After centrifugation for $10 \mathrm{~min}$ at $7500 \mathrm{rpm}$, the precipitate was resuspended in 180 $\mu 1$ ATL buffer (tissue lysis) and $20 \mu \mathrm{l}$ proteinase $\mathrm{K}$ was added. After incubation at $56^{\circ} \mathrm{C}$ for $15 \mathrm{~min}$ and centrifugation for $1 \mathrm{~min}, 200 \mu \mathrm{l}$ buffer AL was added and further incubated at $70^{\circ} \mathrm{C}$ for $10 \mathrm{~min}, 200 \mu \mathrm{l}$ ethanol $100 \%$ were added, then centrifuged for $1 \mathrm{~min}$. All microcentrifuge tubes were transferred to spin column, then centrifuged for $1 \mathrm{~min}$ and discarded the tube containing the filtrate. At the last, $200 \mu \mathrm{l} \mathrm{AE}$ (elution buffer) was added, incubated for $1 \mathrm{~min}$ at room temperature and centrifuged for $1 \mathrm{~min}$. Extracted DNA was stored at $-20^{\circ} \mathrm{C}$ until PCR was performed (Rushdy et al., 2007 modified).

Genotypic detection of bla genes by polymerase chain reaction ( $P C R$ )

Molecular detection of $b l a_{\mathrm{TEM}}$ and $b l a_{\mathrm{SHV}}$ were performed by using PCR analysis. Specific primers were designed for the detection of these genes (Metabion International AG, Germany) as shown in Table 1.
PCR amplification was performed in $25 \mu \mathrm{l}$ master mix $2 \mathrm{X}$ concentration $(5 \mu$ of $10 \mathrm{X}$ PCR buffer, $1.5 \mathrm{mM} \mathrm{MgCl}, 400 \mu \mathrm{M}$ dNTP, 1 unit Taq DNA polymerase), $2 \mu$ of each primer $10 \mathrm{pmol} / \mu \mathrm{l}$ (Promega, USA), $5 \mu$ l of the DNA extracted in a total volume of $50 \mu$ l with sterile $\mathrm{H}_{2} \mathrm{ODEPC}$ treated. The cycling conditions for detection of $b l a_{\text {TEM }}$ and $b l a_{\mathrm{SHV}}$ were done by Applied Biosystems Veriti 96-well Thermal Cycler (Puspanadan et al., 2013). The PCR products were subsequently loaded onto $1.5 \%$ agarose gel (vivantis, USA) and electrophoresis was performed in $1 \mathrm{X}$ TBE buffer at $100 \mathrm{~V}$ for about $30 \mathrm{~min}$. The gels were then stained with $2 \mu$ l ethidium bromide $10 \mathrm{mg} /$ $\mathrm{ml}$ (Sigma, USA). DNA bands were visualized (UVPdual- intensity transilluminator, model: TM-20) at wavelength $312 \mathrm{Nm}$ and photographed by UVP-gel documentary system (Rushdy et al., 2007).

\section{Sequencing of DNA fragment}

Sequencing was done using "ABI 3730xl DNA sequencer" and Sequence Analysis Software v3.1 in GATC Company, Germany. The sequences and homology of the two genes were done by Basic Local Alignment Search Tool (BLAST) and BLAST nucleotide (BLASTN 2.2.13) software and compared to GenBank database.

\section{Preparation of Glycyrrhizic acid nanoparticle}

One mg Glycyrrhizic acid (GA) solution (Xi'an fujie pharmaceutical Co, China) was added to 1-ethyl-3-(3-dimethyl aminopropyl) carbodiimide hydrochloride (Sigma-Aldrich, USA) and N-hydroxysuccinimide (SigmaAldrich, USA), they were dissolved in dimethylformamide (Amresco, USA). 2\% chitosan was mixed with acetic acid and precipitated using acetone, then washed with $60 \%$ ethanol and ether. Then vacuum drying was done for the final product (Cheng et al., 2014). Nano Glycyrrhizic acid was scanned by scanning electron microscope.

TABLE 1 . The sequences of the specific primers used to amplify regions of $b l a_{\mathrm{TEM}}$ and $b l a_{\mathrm{SHV}}$ genes.

\begin{tabular}{llcccc}
\hline Primer & & Nucleotide Sequences & No. Of primer (bp) & $\mathbf{T m}^{\mathbf{0}} \mathbf{C}$ & Product size (bp) \\
\hline \multirow{2}{*}{ TEM } & Forward & CATCGAGCTGGATCTCAACA & 20 & $58^{\circ} \mathrm{C}$ & \\
& Reverse & TTGCCGGGAAGCTAGAGTAA & 20 & $58^{\circ} \mathrm{C}$ & 478 \\
\multirow{2}{*}{ SHV } & Forward & CTTTCCCATGATGAGCACCT & 20 & $58^{\circ} \mathrm{C}$ & \\
& Reverse & GGGGTATCCCGCAGATAAAT & 20 & $58^{\circ} \mathrm{C}$ & 606 \\
\hline
\end{tabular}


Screening for antibacterial activity of different concentrations of Glycyrrhizic acid nanoparticle, a standard inoculum of multi-drug resistant $K$. pneumoniae bacterial isolate was subcultured on Mueller-Hinton agar (Oxoid, UK) and incubated at $37^{\circ} \mathrm{C}$ for $24 \mathrm{~h}$. (Cappuccino \& Sherman, 1995).

The lowest concentration of the antimicrobial agent which prevents the visible growth of a microorganism in a broth dilution susceptibility test is defined as minimal inhibitory concentration (MIC), while the minimal bactericidal concentration (MBC) was determined, after determining the results for the MIC, as the lowest concentration that achieved as $99.9 \%$ decrease in viable bacterial growth (Rushdy \& Othman, 2011). Different dilutions of Glycyrrhizic acid nanoparticles were prepared in $1 \%$ Dimethyl sulfoxide (DMSO) (10, $20,30,40,50,60,70,80,90$ and $100 \mu \mathrm{g})$. Wells were made using sterile borer and were loaded with $0.45 \mu \mathrm{l}$ of each concentration, then placed in incubator at $37^{\circ} \mathrm{C}$ overnight. The diameter of the inhibition zones was taken as a measure of the antibacterial activity (Othman \& Hussein, 2015).

Two tubes (one contained $2 \mathrm{ml}$ brain heart broth, $20 \mu \mathrm{l}$ bacterial suspension and $50 \mu \mathrm{l}$ Glycyrrhizic acid nanoparticles while the other tube was the control without Glycyrrhizic acid nanoparticles) were incubated in duplicates at $37^{\circ} \mathrm{C}$ for $24 \mathrm{~h}$. Bacterial growth was measured on spectrophotometer (T80 UV/VIS Spectrometer, United Kingdom) by optical density at $600 \mathrm{~nm}$.

\section{$\underline{\text { Results }}$}

Eighty isolates out of the $150(53.3 \%)$ collected from two different hospitals were identified as K. pneumoniae in the period from April 2016 to January 2017. Four were isolated from pus, 15 from blood, 10 from urine and 51 from sputum samples. These isolates were first morphologically identified as large dome-shaped colonies on Blood, lactose fermenting mucoid colonies on MacConkey agar plates. Biochemical characteristics of these isolates were performed by analytical profile index (API 20E) where positivity for o-nitrophenyl- $\beta$-Dgalactoside, Lysine Decarboxylase, Citrate Test, Urease Test, Voges-Proskauer Test and sugar (Glucose, Sorbitol, Mannitol,Rhamnose, Inositol, Sucrose, Arabinose, Melibiose and Amygdalin) fermentation. The clinical specimens collected from different hospital units are shown in Table 2.
TABLE 2. The frequency of $K$. pneumoniae in hospital units.

\begin{tabular}{lcc}
\hline Hospital unit & Numbers & $\begin{array}{c}\text { Percentage } \\
(\%)\end{array}$ \\
\hline Surgery & 16 & 20.0 \\
Laboratory & 39 & 48.75 \\
Coronary Care & 5 & 6.25 \\
Intensive Care & 20 & 25.0 \\
Total & 80 & 100 \\
\hline
\end{tabular}

Fifty isolates $(62 \%)$ out of 80 Klebsiella pneumoniae were from males and $30(38 \%)$ were from females. Figure 1 shows the distribution of Klebsiella pneumoniae infection in different age groups and Fig. 2 shows the distribution of Klebsiella pneumoniae infection in relation to patient sex and type of specimen.

The antibiotic susceptibility testing of the eighty $K$. pneumoniae isolates showed high susceptibility to Carbapenems (Imipenem 88.75\% and Meropenem 88.75), Chloramphenicol 96.25\%, Aminoglycosides (Amikacin 68.75\% and Gentamycin 73.75\%), Trimethoprim/ Sulphamathoxazole $62.5 \%$ and Quinolones (Ciprofloxacin 60\%). On the other hand, $K$. pneumoniae strains were found to be highly resistant to Penicillin group (Ampicillin 86.25\%, Piperacillin $62.5 \%$ and Amoxicillin/ Clavulanic acid 81.25\%), Cephalosporins group (Cefaclor85\%, Ceftazidime $92.5 \%$ and Ceftriaxone 100\%), Quinolones group (Nalidixic acid $68.75 \%$ ) and Rifampin $100 \%$ (Fig. 3).

Seventy one percent (57/80) isolates of $K$. pneumoniae were found to be multi-drug resistant strains and $63 \%(36 / 57)$ also found to contain the ESBL enzymes, so they were tested by double disk synergy test for the production of extendedspectrum $\beta$-lactamases (Table 3 and Fig. 4). The figure illustrates double-disk synergy test for amoxicillin/clavulanic acid 20/10 $\mu$ g, ceftazidime $30 \mu \mathrm{g}$, cefotaxime $30 \mu \mathrm{g}$, ceftriaxone $30 \mu \mathrm{g}$ and aztreonam $30 \mu \mathrm{g}$.

Genotypic analysis for $b l a_{\mathrm{TEM}}$ and $b l a_{\mathrm{SHV}}$ genes by polymerase chain reaction. The 36 multi-drug resistant $K$. pneumoniae isolates which were ESBL positive subjected to the detection of TEM and SHV genes. Genotypic characterization by PCR revealed presence of $b l a_{\mathrm{TEM}}$ and $b l a_{\mathrm{SHV}}$ genes at $478 \mathrm{bp}$ and 606bp, respectively (Fig. 5 and 6). 


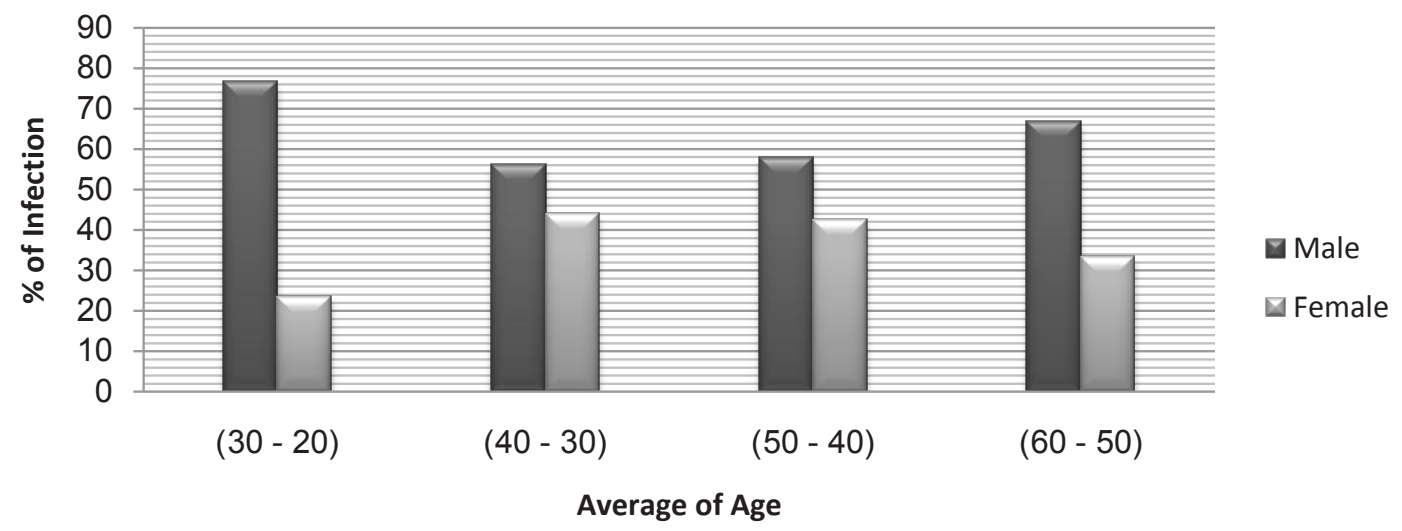

Fig. 1. Prevalence of $K$. pneumoniae in clinical samples with co-relation to patient age.

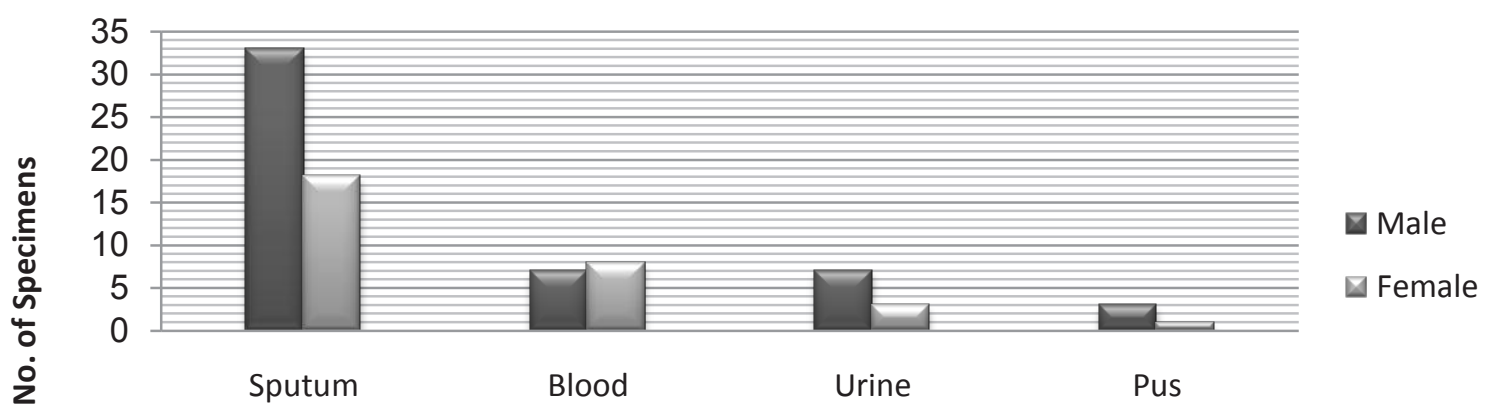

Type of Specimen

Fig. 2. Prevalence of $K$. pneumonie in clinical samples with co-relation to patient sex and type of specimen.

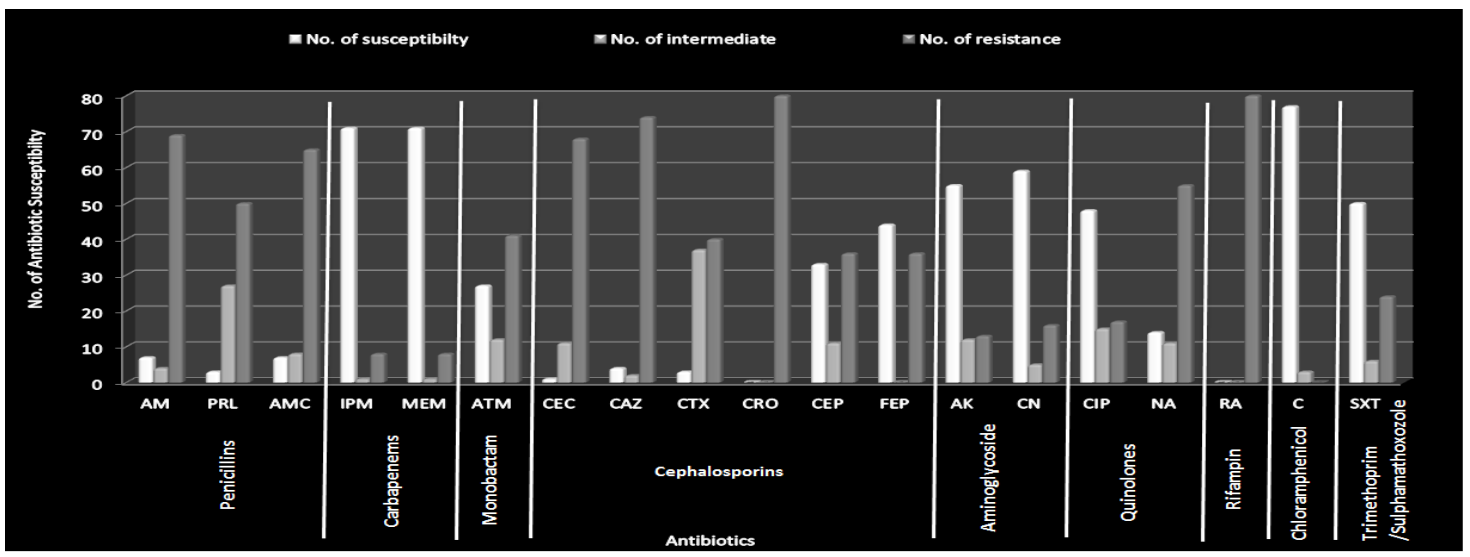

Fig. 3. Number of susceptible (S), intermediate (I) and resistance (R) Klebsiella pneumoniae isolates against different antibiotic groups.

Nineteen isolates out of $36(52.8 \%)$ harbored TEM geneand 26 isolates $(72.2 \%)$ harbored SHV gene, while nine isolates out of the 36 ESBL producing $K$. pneumoniae isolates $(25 \%)$ harbored both genes. 


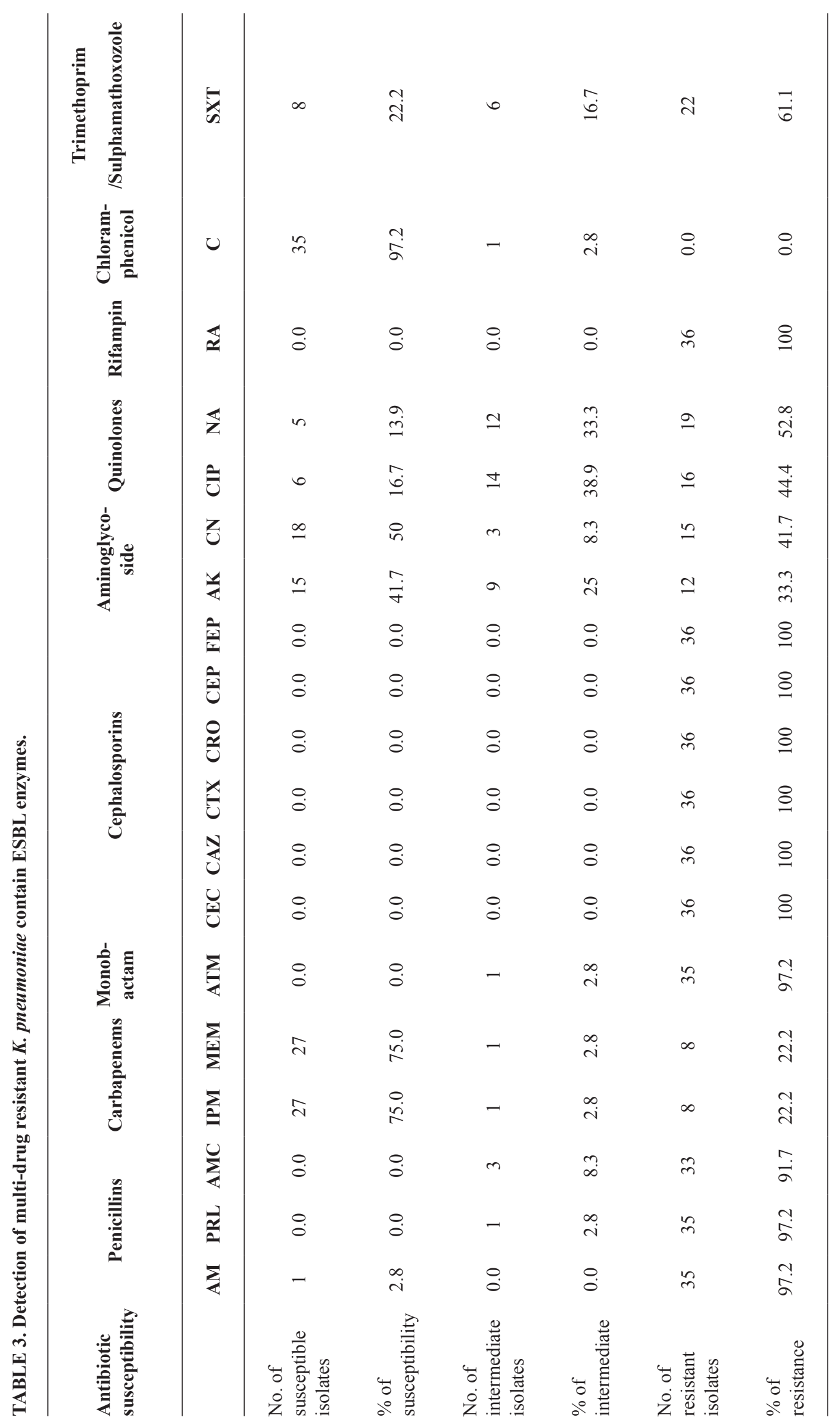

Egypt. J. Microbiol. Vol. 53 (2018) 


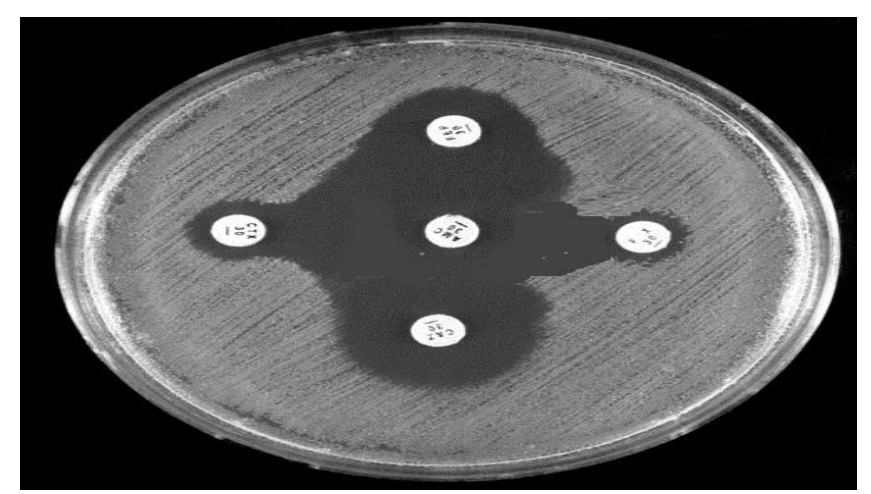

Fig. 4. Double-disk synergy test for detection of $K$. pneumoniae producing ESBL enzyme.

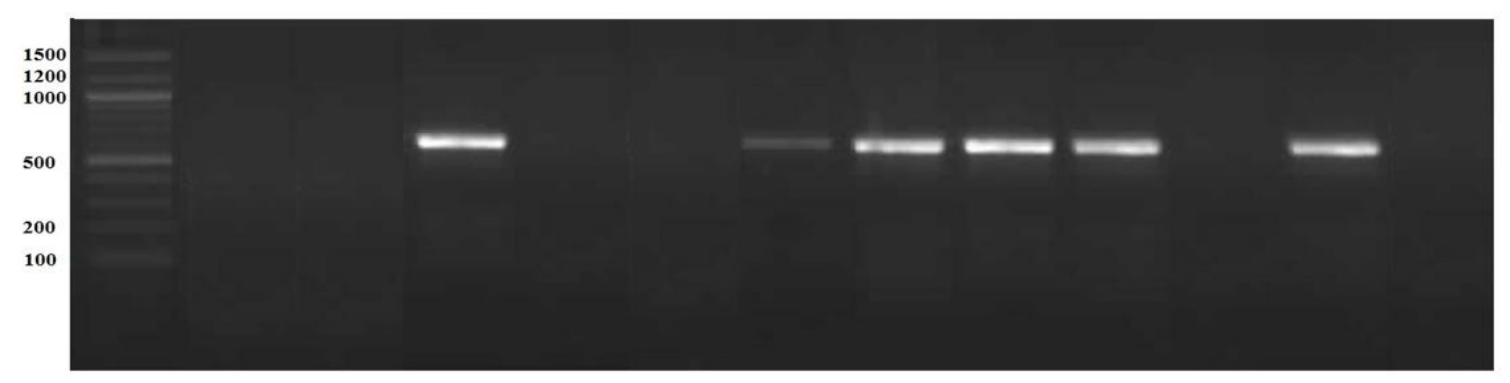

Fig. 5. Agarose gel (1.5\%) electrophoresis of amplified 478bp DNA fragment TEM gene of K. pneumoniae.

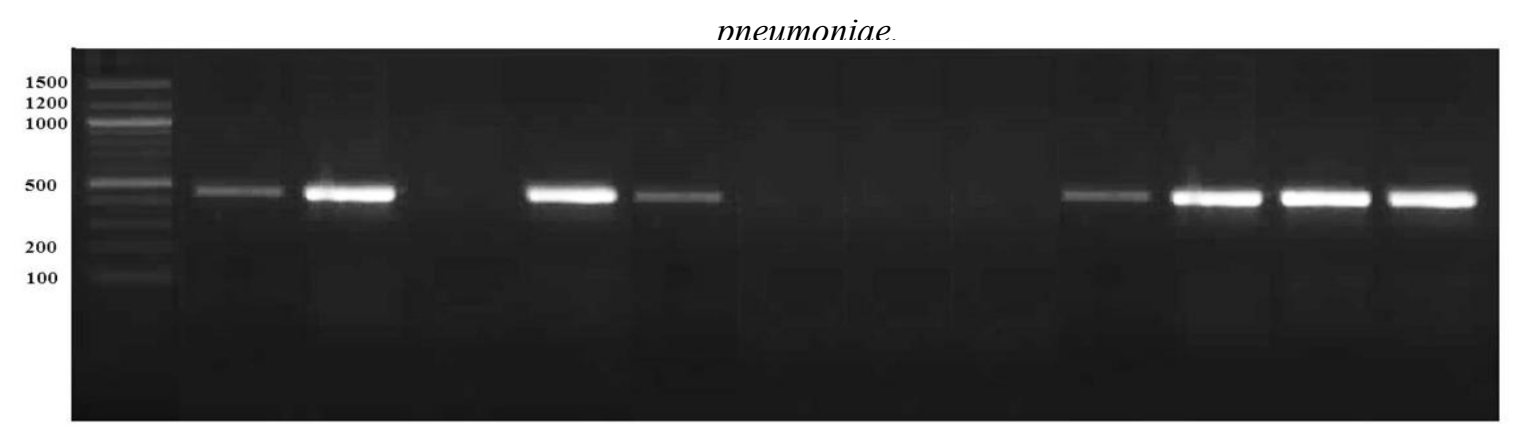

Fig. 6. Agarose gel (1.5\%) electrophoresis of amplified 606bp DNA fragment SHV gene of $\mathrm{K}$. pneumoniae.

Nucleic acid sequencealignment of $b l a_{\text {TEM }}$ and $b l a_{\mathrm{SHV}}$ genes for the Egyptian $K$. pneumoniae isolates was done on gene bank database on the World Wide Web and revealed the presence of some mutations. Table 4 illustrated three types of mutations in $b l a_{\mathrm{TEM}}$ including deletion, substitution and insertion, while in case of $b l a_{\mathrm{SHV}}$ gene there were two types of mutations including deletion and substitution (Table 5).

Effect of Glycyrrhizic acid nanoparticles on ESBL producing Klebsiella pneumoniae, different concentrations of Glycyrrhizic acid nano-particle were tested for their antibacterial activity on three ESBL producing $K$. pneumoniae isolates, one contains TEM gene, one contains SHV gene and one contains both genes. Nano Glycyrrhizic acid was scanned by scanning electron microscope (Fig. 7).

The Table 6 shows that the minimal bactericidal concentration (MBC) for the bacterial isolates which contain both TEM or SHV genes and that containing both genes was $10 \mu \mathrm{g} / \mathrm{ml}$ Nano Glycyrrhizic acid. The minimal inhibitory concentration (MIC) for the isolate that contains TEM gene was $20 \mu \mathrm{g} / \mathrm{ml}$ and that for the isolate contains SHV gene was $40 \mu \mathrm{g} / \mathrm{ml}$ while that for the isolate containing both genes was $30 \mu \mathrm{g} / \mathrm{ml}$. 
TABLE 4. Type of mutations detected in a complex region of TEM gene of Egyptian isolates of K. pneumoniae compared to the same region of $K$. pneumoniae included in the GenBank database.

\begin{tabular}{|c|c|c|c|c|}
\hline \multirow{3}{*}{$\begin{array}{l}\text { Position } \\
\text { (Query) }\end{array}$} & \multicolumn{4}{|c|}{ Type of mutation } \\
\hline & Deletion & \multicolumn{2}{|c|}{ Substitution } & Insertion \\
\hline & & Inversion & Transversion & \\
\hline 436 & $-\mathrm{T}$ & & & \\
\hline 437 & $-\mathrm{A}$ & & & \\
\hline 438 & & $\mathrm{~A} \rightarrow \mathrm{G}$ & & \\
\hline 442 & & & & $+\mathrm{C}$ \\
\hline 443 & & & & $+\mathrm{C}$ \\
\hline 452 & & & $\mathrm{~A} \rightarrow \mathrm{C}$ & \\
\hline
\end{tabular}

TABLE 5. Type of mutations detected in a complex region of SHV gene of Egyptian isolates of K. pneumoniae compared to the same region of $K$. pneumoniae included in the GenBank database.

\begin{tabular}{llcl}
\hline Position & \multicolumn{2}{c}{ Type of mutation } \\
\hline (Query) & Deletion & Substitution & \\
\hline & & Inversion & Transversion \\
\cline { 2 - 4 } 100 & & $\mathrm{~T} \rightarrow \mathrm{G}$ \\
152 & $\mathrm{~T} \rightarrow \mathrm{C}$ & \\
497 & $\mathrm{G} \rightarrow \mathrm{A}$ & \\
524 & $\mathrm{~T} \rightarrow \mathrm{C}$ & \\
568 & & $\mathrm{G} \rightarrow \mathrm{C}$ \\
571 & & $\mathrm{C}$ & \\
576 & & $\mathrm{~A} \rightarrow \mathrm{T}$ \\
578 & & $\mathrm{~A} \rightarrow \mathrm{C}$ \\
\hline
\end{tabular}

TABLE 6. Antibacterial activity of different concentrations of Glycyrrhizic acid nano particle on ESBL producing K. pneumoniae isolates.

\section{Concentrations of}

Glycyrrhizic acid

Measuring on spectrophotometer at 600nm (optical density)

nanoparticle $(\mu \mathrm{g} / \mathrm{ml})$

\begin{tabular}{lccc}
\hline ESBL producing $\boldsymbol{K}$. & $\begin{array}{c}\text { ESBL producing } \\
\text { K. pneumoniae } \\
\text { heuve SHV gene }\end{array}$ & $\begin{array}{c}\text { ESBL producing } \boldsymbol{K} . \\
\text { pneumoniae } \text { have both TEM, } \\
\text { SHV genes }\end{array}$ \\
\hline 10 & $0.057(\mathrm{MBC})$ & $0.077(\mathrm{MBC})$ & $0.069(\mathrm{MBC})$ \\
20 & $0.073(\mathrm{MIC})$ & 0.086 & 0.072 \\
30 & 0.200 & 0.088 & $0.082(\mathrm{MIC})$ \\
40 & 0.084 & $0.092(\mathrm{MIC})$ & 0.099 \\
50 & 0.118 & 0.357 & 0.083 \\
60 & 0.096 & 0.104 & 0.081 \\
70 & 0.107 & 0.113 & 0.090 \\
80 & 0.570 & 0.111 & 0.105 \\
90 & 0.167 & 0.160 & 0.296 \\
100 & 0.108 & 0.435 & 0.256 \\
\hline
\end{tabular}




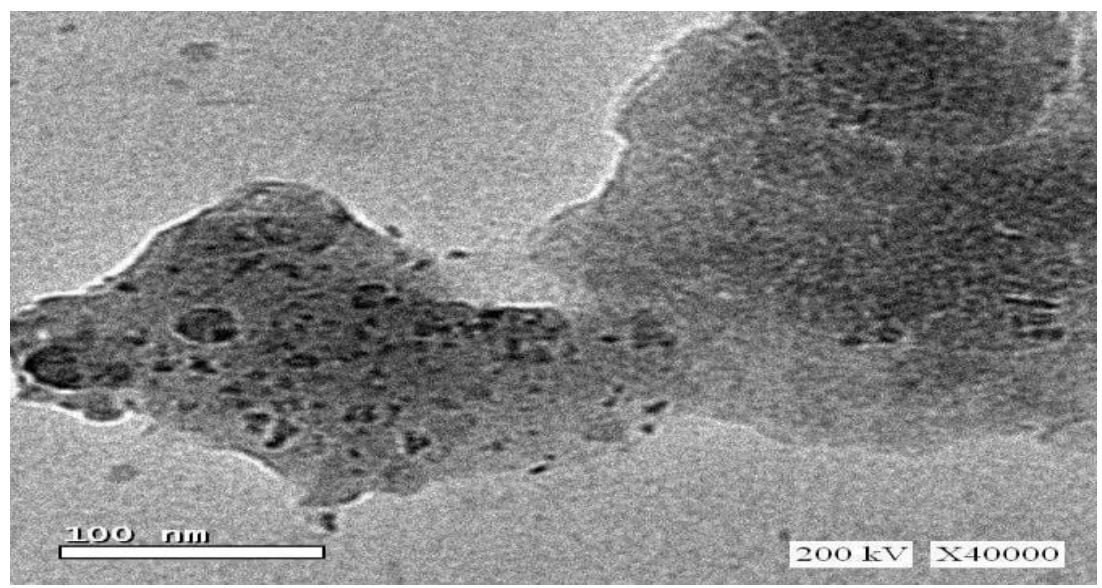

Fig. 7. Scanning electron microscope image of the nano Glycyrrhizic acid, a spherical in shape.

\section{Discussion}

The present study reveals that $K$. pneumoniae was detected in $53.3 \%$ of the total collected samples. Seventy one percent of them were found to be multi-drug resistant strains. Conversely to this result, Archana \& Harsh (2011) illustrated that $11.8 \%$ confirmed $K$. pneumoniae isolates were further tested for antimicrobial drug sensitivity and almost fifty percent of them were found to be multidrug resistant. A possible subtle difference with 'non-Egyptian' isolates of $K$. pneumonia that patients neglect the time and right dose of treatment and take medication without consulting the doctor until bacterial genes develop resistance.

In the present study, Klebsiella pneumoniae isolates was predominant in males $(62 \%)$ than in females $(38 \%)$. K. pneumoniae infection seen in patients aged 20-60. Conversely, to this result Shashidhar Vishwanath et al. (2013) illustrated that the high percentage of infection in patients admitted to Iran hospital were females with a percentage (45.45\%) than males (31.57\%), Klebsiella pneumoniae infection seen in persons aged 45-60. This may be due to the Egyptian Traditions is that females are used to stay at home so they are protected from infection while males are responsible for working and may have bad habits like smoking.

The current study indicated that non ESBL producing $K$. pneumoniae isolates were found to be highly susceptible to Carbapenems (imipenem $88.75 \%$ and meropenem 88.75 ), chloramphenicol 96.25\%, Aminoglycosides (amikacin 68.75\% and gentamycin 73.75\%), Trimethoprim/ Sulphamathoxazole 62.5\% and Quinolones (ciprofloxacin 60\%). On the other hand, ESBL producing $K$. pneumoniae isolates were found to be highly susceptible to Carbapenems (imipenem $75.0 \%$ and meropenem 75.0), chloramphenicol 91.7\% and aminoglycosides (amikacin 41.7\% and gentamycin $50.0 \%$ ).

In previous studies, K. pneumoniae strains were found to be highly susceptible to aminoglycosides and quinolones. On the other hand over $60 \%$ strains were resistant to chloramphenicol, tetracycline and cephalosporins (ceftizoxime and cefotaxime). Cephalosporins were the drug of choice in combination with aminoglycosides to treat Klebsiella infection (Archana \& Harsh, 2011). Carbapenems are stable in the presence of hydrolytic effects of ESBLs, which may explain the consistent finding that $>98 \%$ of ESBLproducing organisms retain susceptibility to either imipenem or meropenem (Babini \& Livermore, 2000; Goossens, 2001 and Winokur et al., 2001).

The present study showed that 36 isolates of $K$. pneumoniae out of eighty bacterial isolates were found to be ESBL producing $K$. pneumoniae (sputum $\mathrm{n}=26$ and blood $\mathrm{n}=10$ ). They also showed a positive result for double disk synergy test for the production of extended spectrum $\beta$-lactamases. These ESBL multi-drug resistant $K$. pneumoniae were found to be highly resistance to Penicillins group (Ampicillin 97.2\%, Piperacillin 97.2\% and Amoxicillin/Clavulanic acid 91.7\%), Monobactam group (Aztreonam $97.2 \%)$, Cephalosporins group ( $2^{\text {nd }}$ generation $100 \%, 3^{\text {rd }}$ generation $100 \%$ and $4^{\text {th }}$ generation 
100\%), Rifampin 100\%, Quinolones group (Ciprofloxacin $44.4 \%$ and Nalidixic acid 52.8\%) and Trimethoprim /Sulphamathoxozole 61.1\%. Positive ESBLs are predominantly responsible for drug resistance to $\beta$-lactam antibiotics (Liu et al., 2014 and Lahlaoui et al., 2014). The chromosomally encoded $\beta$ - lactamases could be responsible for this intrinsic resistance (Sahly et al., 2004). Overall resistance was high on account of the production of extended spectrum $\beta$-lactamases (ESBLs) by the K. pneumoniae.

ESBLs are grouped into four classes A, B, C and D enzymes. Temoneira (TEM) and sulfhydryl variable (SHV) are class A ESBLs (Shahid et al., 2011). The most common ESBLs observed in the isolated $K$. pneumoniae plasmids are encoding Temoniera (TEM) and Sulfhydryl variable $(\mathrm{SVH})$, which are active against Cephalosporins (Vuotto et al., 2014) so in the present study, PCR was performed to determine the presence of TEM and SHV genes as antibiotic resistance factors of K. pneumoniae.

Plasmids encoding Temoniera (TEM) and Sulfhydryl variable (SVH) ESBLs are the most common to be found in isolated $K$. pneumoniae, which are active against cephaloporins. The plasmids that encode the ESBL genes also have been found to carry genes that express resistance for drugs other than beta-lactams, such as aminoglycosides (Vuotto et al., 2014). So in this study the detection TEM and SHV genes was used as a mark of multi-drug resistant in $K$. pneumoniae.

The results indicated that $52.8 \%$ contained the TEM gene and $72.2 \%$ contained the SHV gene, while $25 \%$ of the multi-drug resistant isolated has both genes (TEM and SHV). Multidrug-resistant (MDR) and extended-spectrum $\beta$-lactamase producing Klebsiella pneumoniae pose serious antibiotic management problem as resistance genes are easily transferred from one organism to another (Lim et al., 2009).

Fouzia \& Damle (2015) made a study on the amplification of $b l a_{\mathrm{TEM}}$ and $b l a_{\mathrm{SHV}}$ and she found that seventy percent of isolates showed a presence of TEM gene, while $50 \%$ isolates showed a presence of SHV gene and 20\% isolates had both $b l a_{\mathrm{TEM}}$ and $b l a_{\mathrm{SHV}}$ genes.

In a study by Amita Jain \& Rajesh Mondal using the same set of primers, they found a presence of $b_{\text {beM }}$ gene in ESBL producing Klebsiella sp. as more common $(48.4 \%)$ than bla $_{\mathrm{SHV}}(20.3 \%)$ gene. while $(26.5 \%)$ isolates presented both TEM and SHV genes (Jain \& Mondal, 2008).

The present study revealed that sequencing alignment of $b l a_{\mathrm{TEM}}$ and $b l a_{\mathrm{SHV}}$ genes showed some mutations in both genes such as deletion and substitution in both genes and insertion in TEM gene only. The mutation presented in both genes may be due to the excess or improper use of antibiotics in Egypt.

Glycyrrhizic acid interferes with arylamine $\mathrm{N}$-acetyltransferase activity in bacteria, thus showing antibacterial effects against Klebsiella spp. (Tanaka et al., 2001 and Krausse et al., 2004).

Glycyrrhizic acid should be considered, one of the proposed chemopreventive drugs, that could inhibit arylamine $\mathrm{N}$-acetyltransferase (NAT) activity in Klebsiella pneumoniae. The NAT activity in $K$. pneumoniae was inhibited by Glycyrrhizic acid in a dose-dependent manner (Hsueh-Hsia et al., 1997).

\section{Conclusion}

The present study showed that nano Glycyrrhizic acid was found to be highly effective on MDR K. pneumoniae. The minimal inhibitory concentration (MIC) for the isolate that contains TEM gene was $20 \%$ and that for the isolate contains SHV gene was $40 \%$ while that for the isolate containing both genes was $30 \%$.

\section{References}

Archana, S.S. and Harsh, V.B. (2011) Prevalence of antimicrobial drug resistance of Klebsiella pneumoniae in India. International Journal of Bioscience, Biochemistry and Bioinformatics, 1 (3), 211-215.

Arivett, B.A., Ream, D.C., Fiester, S.E., Mende, K., Murray, C.K. and Thompson, M.G. (2015) Draft genome sequences of Klebsiella pneumoniae clinical type strain ATCC 13883 and three multidrug-resistant clinical isolates. Genome Announcements, 3(1), e01385-14.

Babini, G.S. and Livermore, D.M. (2000) Antimicrobial resistance amongst Klebsiella spp. collected from intensive care units in Southern and Western Europe in 1997-1998. J. Antimicrob Chemother. 45, 183-9.

Baveja, C.V. (2012) "Textbook of Microbiology", pp. $254-255,4^{\text {th }}$ ed. Arya Publications Revised.

Cappuccino, J.G. and Sherman, N. (1995) "Microbiology Lab Manual". USA, Benjamin- 
Cummings Publishing Company, 477p.

Cheng, M., Chen, H., Wang, Y., Xu, H., He, B., Han, J. and Zhang, Z. (2014) Optimized synthesis of glycyrrhetinic acid-modified chitosan 5-fluorouracil nanoparticles and their characteristics. International Journal of Nanomedicine, 9(1), 695-710. https:// doi.org/10.2147/IJN.S55255

Cheesbrough, Monica (2000) Microbiological tests. In: "District Laboratory Practice in Tropical Countries", Part-2, low price ed. Cambridge, pp.71141.

Clinical Laboratory Standard Institute "CLSI" (2014) Performance Standards for Antimicrobial Susceptibility Testing. Twenty-Fourth Informational Supplement, M100-S24, 34(1).

Cruickshank, R. (1980) "Medical Microbiology", $12^{\text {th }}$ ed., 170-189 (revised reprient), Edinburg: Churchill Livingstone.

Fouzia, B. and Damle, A.S. (2015) Prevalence of bla and bla $_{S H V}$ genes in clinical isolates of Klebsiella pneumoniae in a tertiary care hospital. J. Microbiol. Biotech. Res. 5(1), 1-7.

Goossens, H. (2001): MYSTIC program: Summary of European data from 1997 to 2000. Diagn Microbiol Infect. Dis. 41,183-9.

Hsueh-Hsia, Lo, Yee-Sang, Yen, Sue-Er Hsieh and Jing-Gung Chung (1997) Glycyrrhizic acid inhibits arylamine N- acetyltransferase activity in Klebsiella pneumoniae in vitro. Journal of Applied Toxicology, 17(6), 385-390.

Jain, A. and Mondal, R. (2008) TEM \& SHV genes in extended spectrum $\beta$-lactamase producing Klebsiella spp. and their antimicrobial resistance pattern. Indian J. Med. Res. 128, 759-764.

Jarlir, V., Nicolas, M.H., Fournier, G. and Philippon, A. (1988) ESBLs conferring transferable resistance to newer $\beta$-lactam agents in enterobacteriaceae: Hospital prevalence and susceptibility patterns. Review Infectious Disease, 10, 867-878.

Jian-Yuan, L., Hong-Yan, C., Liu, P. and Gen-Hong, C. (2014) Glycyrrhizic acid in the treatment of liver diseases: Literature review. Journal of Biomedicine and Biotechnology, 1, 872139. DOI: $10.1155 / 2014 / 872139$

Freeman, J.T., Nimmo, J., Gregory, E., Tiong, A., De Almeida, M., McAuliffe, G.N. and Roberts, S.A. (2014) Predictors of hospital surface contamination with extended-spectrum Beta-lactamase producing Escherichia coli and Klebsiella pneumoniae: Patient and organism factors. Antimicrob Resist Infect Control, 3(5), 1-7.

Krausse, R., Bielenberg, J., Blaschek, W. and Ullmann,
U. (2004) In vitro anti-Helicobacter pylori activity of Extractum liquiritiae, glycyrrhizin and its metabolites. J. Antimicrob. Chemother. 54(1), 243-6.

Kumar, V., Sun, P., Vamathevan, J., Li, Y., Ingraham, K., Palmer, L. and Brown, J.R. (2011) Comparative genomics of Klebsiella pneumoniae strains with different antibiotic resistance profiles. Antimicrobial Agents and Chemotherapy, 55(9), 4267-4276. http://doi.org/10.1128/AAC.00052-11

Lahlaoui, H., Ben Haj Khalifa, A. and Ben Moussa, M. (2014) Epidemiology of Enterobacteriaceae producing CTX-M type extended spectrum â-lactamase (ESBL). Med. Mal. Infect. 44, 400-404.

Lim, K.T., Yeo, C.C., Yasin, R.M., Balan, G. and Thong, K.L. (2009) Characterization of multidrug-resistant and extended-spectrum $\beta$-lactamase-producing Klebsiella pneumoniae strains from Malaysian hospitals. J. Med. Microbiol. 58, 1463-1469. doi: 10.1099/jmm.0.011114-0.

Liu, L., Wang, X., An, S. and Zhang, X. (2014)Genetic environment of $\beta$-lactamase genes of extendedspectrum $\quad \beta$-lactamase-producing Klebsiella pneumoniae isolates from patients with lower respiratory tract infection in China. Chin. Med. J. 127, 2445-2450.

Onur, M.A. and Durak, Y. (2009) Investigations of some antibiotics susceptibilities, plasmid profiles and ESBL characteristic of Klebsiella pneumoniae isolated from urinary system infections. World Applied Sciences Journal, 6(5), 630-636.

Mustafa, M.G., Areej, M. and El-Mahdy, Rasha F.B. (2017) Association between virulence factors and extended spectrum beta-lactamase producing Klebsiella pneumoniae compared to nonproducing isolates. Interdisciplinary Perspectives on Infectious Diseases, 7279830, 14.

Namratha, K.G., Padiyath Sreeshma, Subbannayya K., Dinesh, P.V. and Hemachandra Champa (2015) Characterization and antibiogram of Klebsiella spp. isolated from clinical specimen in a rural teaching hospital. Scholars Journal of Applied Medical Sciences (SJAMS), 3(2E), 878-883.

Othman, Amal S. and Hussein, M.A. (2015) In vitro antibacterial, antioxidant and hepatoprotective effect of curcumin-zinc oxide nano particles in combination. International Journal of Pharma and Bio Sciences, 6(4), 105-118.

Papp-Wallace, K.M., Endimiani, A., Taracila, M.A. and Bonomo, R.A. (2011) Carbapenems: Past, present, and future. Antimicrobial Agents and Chemotherapy, 55(11), 4943-4960. http://doi. org/10.1128/AAC.00296-11

Puspanadan, S., Afsah-Hejri, L., John, Y.H.T., 
Rukayadi, Y., Loo, Y.Y., Nillian, E., Kuan, C.H., Goh, S.G., Chang, W.S., Lye, Y.L., Mohd Shahril, N., Yoshitsugu, N., Nishibuchi, M. and Son, R. (2013) Characterization of extended-spectrum $\beta$ lactamases (ESBLs) producers in Klebsiella pneumoniae by genotypic and phenotypic method. International Food Research Journal, 20(3), 14791483.

Qureshi, S. (2015) "Klebsiella Infections Treatment \& Management", M. Bronze (Ed.). Retrieved November 29, 2015, from http://emedicine. medscape.com/article/219907-treatment.

Rushdy, Abeer A., Salama, M.S. and Othman, Amal S (2007) Detection of Methicillin/Oxacillin resistant Staphylococcus aureus isolated from some clinical hospitals in Cairo using Meca/Nuc genes and antibiotic susceptibility profile. International Journal of Agriculture \& Biology, 9(6), 800-806.

Rushdy, Abeer A. and Othman, Amal S. (2011) Bactericidal efficacy of some commercial disinfectants on biofilm on stainless steel surfaces of food equipment. Ann Microbiol. 61, 545-552. DOI 10.1007/s13213-010-0172-7.

Sahly, H., Aucken, H., Benedi, V.J., Forestier, C., Fussing, V., Hansen, D.S., Ofek, I., Podschun, R., Sirot, D., Tomas, J.M., Sandvang, D. and Ullmann, U. (2004) Increased serum resistance in Klebsiella pneumoniae strains producing extended-spectrum beta-Lactamases. Antimicrobial Agents and Chemotherapy journal, 9(48), 3477-3482.

Sahoo, S.K., Dilnawaz, F. and Krishnakumar, S. (2008) Nanotechnology in ocular drug delivery. Drug Discov. Today, 13, 144-151.

Shahid, M., Singh, A., Sobia, F., Rashid, M., Malik, A. and Shukla, I. (2011) blaCTX-M, bla ${ }_{\mathrm{TEM}}$, and $b l a_{\mathrm{SHV}}$ in Enterobacteriaceae from North- Indian tertiary hospital: High occurrence of combination genes. Asian Pac. J. Trop. Med. 4(2), 101-5.
Sharma, V., Agrawal, R.C. and Pandey, S. (2013) Phytochemical screening and determination of antibacterial and anti-oxidant potential of Glycyrrhiza glabra root extracts. J. Environ. Res. Develop. 7(4), 1552-1558.

Shashidhar, Vishwanath, Kiran, Chawla and Anusha, Gopinathan (2013) Multidrug resistant Gramnegative bacilli in lower respiratory tract infectons. Iranian Journal of Microbiology, 4(5), 323-327.

Tanaka, Y., Kikuzaki, H., Fukuda, S. and Nakatani, N. (2001) Antibacterial compounds of licorice against upper airway respiratory tract pathogens. J. Nutr. Sci. Vitaminol. Tokyo, 47(3), 270-3.

Vuotto, C., Longo, F., Balice, M.P., Donelli, G. and Varaldo, P.E. (2014) Antibiotic resistance related to biofilm formation in Klebsiella pneumoniae. pathogens. Pathogens, 3(3), 743-758. http://doi. org/10.3390/pathogens3030743.

Wagner, V., Dullaart, A., Bock, A.K. and Zweck, A. (2006) The emerging nanomedicine landscape. Nat. Biotechnol. 24, 1211-1217.

Winokur, P.L., Canton, R., Casellas, J.M. and Legakis, N. (2001) Variations in the prevalence of strains expressing an extended-spectrum $\beta$-lactamase phenotype and characterization of isolates from Europe, the Americas, and the Western Pacific region. Clin. Infect. Dis. 32(Suppl 2), S94-103.

Yong, J.P. (2012) Advances in studies on the synthesis of Glycyrrhizic acid, Glycyrrhetinic acid derivatives and their biological activities. Lishizhen Medicine and Materia Medica Research, 23(6), 1174-1182.

(Received 7/ 9/2018; accepted 17/10/2018) 


\section{الكثف المعلي لتأثير جزيئات النانو لحمض الجليسريزك ضد بكتيريا الكليسيلة الرئوية

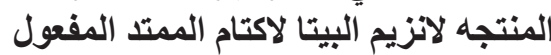

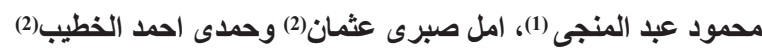

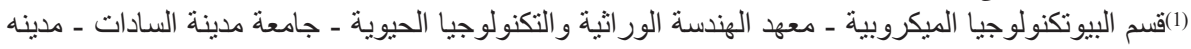

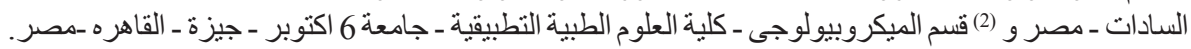

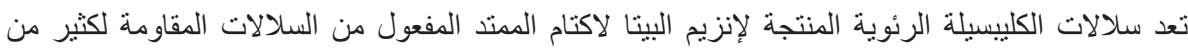

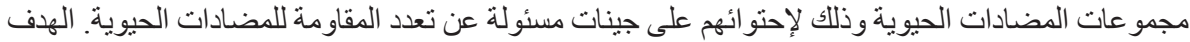

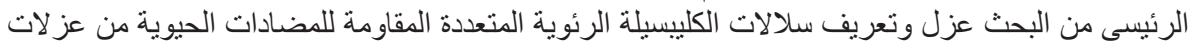

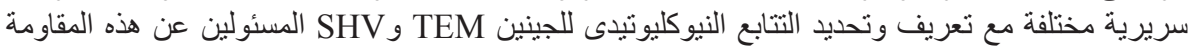

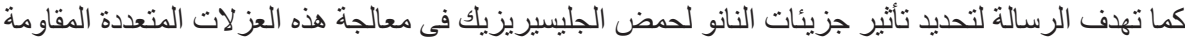

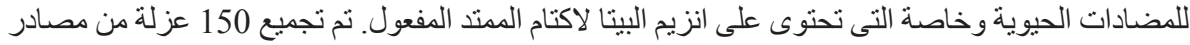

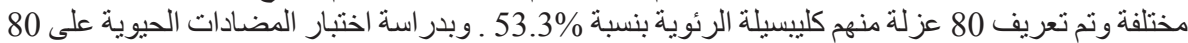

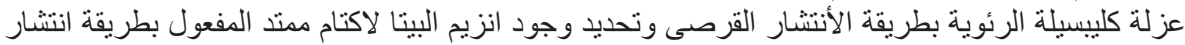

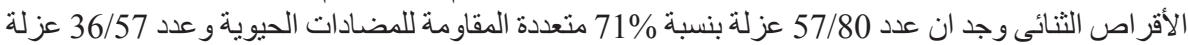

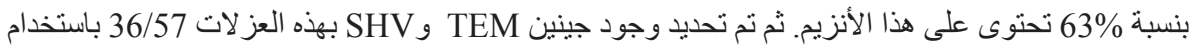
تفاعل البلمرة المتسلسل. اوضحت النتيجة ان

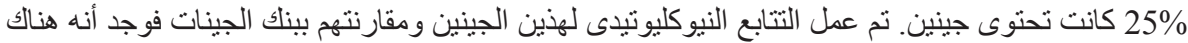

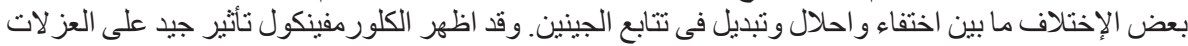

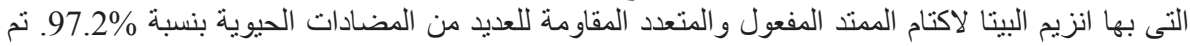

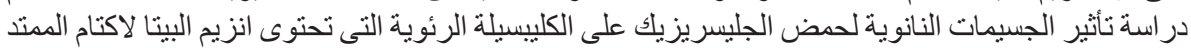

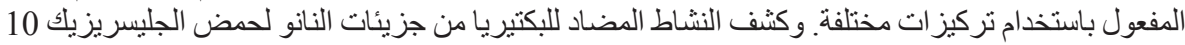
ميكروجرام/ مل هو اقل تركيز قاتل للبكتريا الكليبسيلة الرئوية التى تحتوى انزئن انزيم البيتا لاكتام الممتد المفعول.
} 